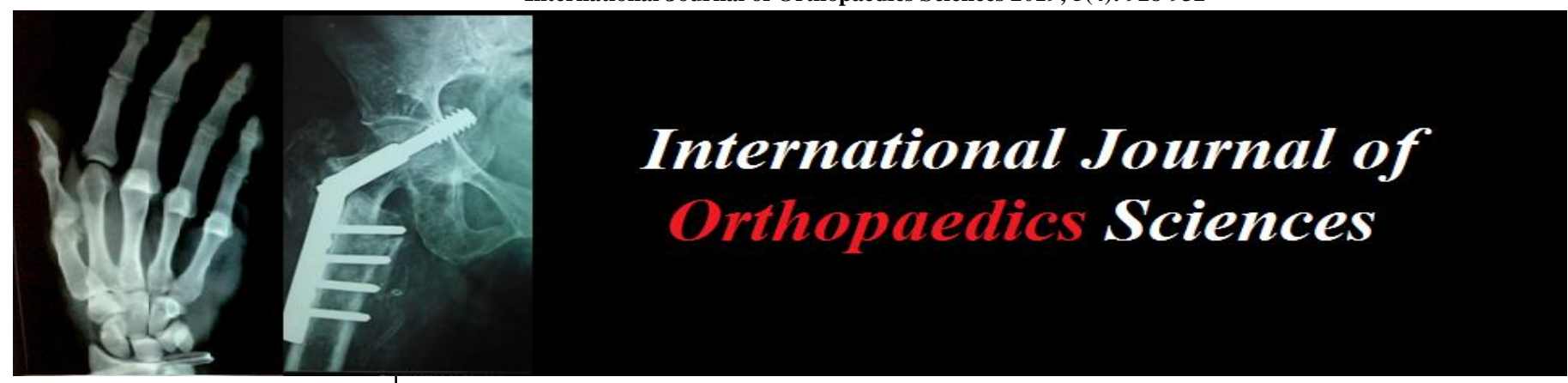

E-ISSN: 2395-1958

P-ISSN: 2706-6630

IJOS 2019; 5(4): 928-932

(C) 2019 IJOS

www.orthopaper.com

Received: 24-08-2019

Accepted: 28-09-2019

Dr. Yeshwanth Subash Department of Orthopaedics Saveetha Medical College and Hospital Thandalam, Chennai, Tamil Nadu, India

Dr. Lydia M

Department of Orthopaedics Saveetha Medical College and Hospital Thandalam, Chennai, Tamil Nadu, India

Dr. Sugumar Natarajan Department of Orthopaedics Saveetha Medical College and Hospital Thandalam, Chennai, Tamil Nadu, India
Corresponding Author: Dr. Yeshwanth Subash Department of Orthopaedics Saveetha Medical College and Hospital Thandalam, Chennai, Tamil Nadu, India

\section{Management of intertrochanteric fractures of the femur with proximal femoral nail: A prospective study}

\author{
Dr. Yeshwanth Subash, Dr. Lydia M and Dr. Sugumar Natarajan
}

DOI: $\underline{\text { https://doi.org/10.22271/ortho.2019.v5.i4p.1800 }}$

\section{Abstract}

Background: Intertrochanteric fractures of the femur are fairly common injuries seen in Orthopaedic practice and have a bimodal age distribution. Various modalities of treatment are available in the management of these fractures. The aim of this study was to evaluate the role of the proximal femoral nail (PFN) in the management of these fractures and to assess the functional outcome using the Harris hip score.

Methods: 30 patients with Intertrochanteric fractures of the femur who were willing for surgery and follow up were included in our study and were treated with proximal femoral nail and were followed up for a 3 year period.

Results: There was a male preponderance seen in our study with the right hip being more commonly affected. The most common mode of injury was slip and fall followed by road traffic accidents. The mean surgical time was 59.03 minutes and the average time to fracture union was 12.4 weeks. The mean Harris hip score was 83.3 and we had excellent results in 5 patients and good results in 12 of them.

Conclusion: Proximal femoral nailing is an effective treatment option in the management of intertrochanteric fractures of the femur and is associated with lesser operating times, minimal blood loss and earlier weight bearing as compared to other fixation methods and rehabilitation of the patients is quite rapid as well leading to a good functional outcome.

Keywords: intertrochanteric fractures; kyles classification; PFN; Harris hip score

\section{Introduction}

Intertrochanteric fractures of the femur are common injuries seen in the Orthopaedic department and have a bimodal age distribution. They account for $50 \%$ of fractures of the proximal femur. In elderly patients, they often result from a trivial injury such slip and fall or fall from a bed due to poor bone stock while in younger individuals, considerable force is required to bring about a fracture and they often result from road traffic accidents or fall from height. The risk factors for intertrochanteric fractures are advancing age, osteoporosis, smoking, dementia, decrease or loss of visual acuity and prolonged physical inactivity. These fractures are often associated with significant mortality and morbidity in the elderly age group due to the fact that the patients often have associated comorbid conditions such diabetes mellitus, hypertension, bronchial asthma as well as renal and cardiac problems ${ }^{[1,2]}$. Hence due to these factors, conservative management have a limited role and is usually only considered in patients who are medically unfit for surgery. Due to the associated comorbid conditions, there is a need for early surgical fixation and mobilization of these patients in order to prevent complications from occurring. Traditionally intertrochanteric fractures were broadly distributed into two groups as stable and unstable types. The stable fracture patterns are simple fractures with no comminution and with a good calcar support posteromedially. The unstable fractures are the ones with comminution and loss of posteromedial support and are quite difficult to reduce and fix due to the unstable fracture pattern and are often associated with poorer functional outcomes. The implants available for the fixation of these fractures are surface implants such as dynamic hip screw (DHS) and proximal femoral locking plates (PFLP) while the intramedullary implants are the gamma nail and the PFN ${ }^{[3,4,5]}$. The DHS was once the gold standard in the fixation of these fractures but they were associated with 
Poorer outcomes in the unstable fracture patterns. PFLP is a good option in unstable fractures but is associated with a wide skin incision, extensive soft tissue dissection with increased blood loss and a longer surgical time and the need to put the patient on non-weight bearing till the fracture has united completely ${ }^{[6,7,8]}$. In this scenario, the PFN seems to provide better solutions and addresses these issues. The aim of this study was to evaluate the functional outcome of these fractures treated with PFN using the Harris hip score and to compare our results with that of other authors as available in literature.

\section{Methods}

This was a prospective study of 30 patients with intertrochanteric fractures who presented between January 2012 to January 2014 treated with PFN with a 3 year follow up period. This study was performed after obtaining clearance from the ethical committee of our institution. All patients with intertrochanteric fractures of the femur willing for surgery and follow up were included in the study while patients with pathological fractures, active infection or inflammation in the affected joint and patients with neurological disorders in the ipsilateral side were excluded. On admission, all patients were evaluated both clinically and radiologically. Standard radiographs of the affected hip in AP and lateral views, pelvis with both hips AP view and chest $\mathrm{x}$ rays were taken. All fractures were classified according to Kyles classification.

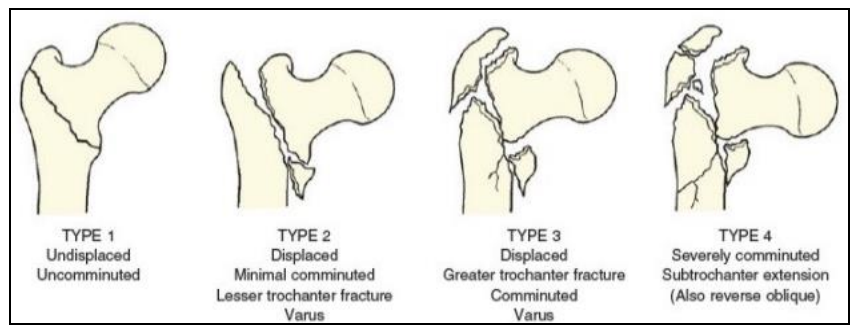

Fig 1: Kyles classification

A thorough history was taken from the patients regarding all associated comorbid conditions and they were documented in the case records. Routine blood investigations were done and the patients were worked up for surgery after obtaining medical and anaesthetic clearance. All surgeries were performed under spinal or combined spinal with epidural anaesthesia with the patient in the supine position on a fracture table under fluoroscopic guidance. Inj cefazolin $1 \mathrm{gm}$ i.v was routinely given for all patients at the time of induction of anaesthesia and was continued for a period of 3 days postoperatively. After placing the patient on the fracture table, traction was given to restore length, external rotation was done to disimpact the fracture site and it was taken into internal rotation for the final reduction and was checked in both AP and lateral views. The limb was then placed in an adducted position in order to facilitate easy entry of the bone awl. A skin incision was made $5 \mathrm{~cm}$ proximal to the tip of the greater trochanter and the skin and subcutaneous tissues were incised in line with it. The fascia and gluteus medius were then split to expose the greater trochanter. A cannulated awl was then placed medial to the tip of the greater trochanter and an entry point was then made in order to pass the guide wire. In certain situations, the entry point was at the fracture site and in such cases a more medial entry which was at the piriformis fossa was preferred in order to prevent distraction of the fracture site during passage of the nail. A guide wire was then passed across the fracture site checking with both AP and lateral views in order to confirm proper medio-lateral and anteroposterior placement. Proximal reaming was then with a $17 \mathrm{~mm}$ reamer and the appropriate size nail was then passed under fluoroscopic guidance. We routinely used a short PFN of length $250 \mathrm{~mm}$ with either a size 10 or $11 \mathrm{~mm}$ depending on the diameter of the femoral canal. A guide wire for the neck screw was then passed as inferior to the femoral neck as possible in order to get a good purchase in the bone followed by the guide wire for the derotation hip pin while ensuring that both wires were midway between anterior and posterior in the lateral flourocopic images. Reaming was then done and the neck screw and the hip pin were then applied with the hip pin being placed 10 to $15 \mathrm{~mm}$ proximal to the neck screw in order to prevent the $\mathrm{Z}$ effect from happening. Distal locking was then performed with the dynamic option chosen for stable fractures and static locking in cases of fractures with communition in order to provide a more stable fixation. Final fluoroscopic imaging was done to assess the position of the nail as well as the neck screw and hip pin in both AP and lateral projections. A wound wash was then given and closure was done in layers and sterile dressing was then applied. Drains were not used in any of our cases. All fractures were amenable to closed reduction and there was no necessity to open up the fracture site in any of the cases. In certain situations when fracture reductions were a little difficult, indirect methods could be applied. In most fracture situations, the proximal fragment is usually in a position of flexion due to the pull of the iliopsoas muscle and so a spike can be passed anterior to the femoral neck and a downward force can be given to reduce the fracture or alternatively an assistant can elevate the shaft of femur distal to the fracture site with a blunt instrument. Postoperatively all patients were made to sit up on the bed on the same evening of surgery and the knee and ankle were actively mobilized. The patients were made to walk on the first or second postoperative day with a walker or crutch support based on the patient pain tolerance or compliance of the patient. Postoperative $\mathrm{x}$ rays of the hip in AP and lateral views were taken to evaluate the quality of the fixation. Assesment of fracture reduction was taken to be good and anatomical if there was less than $5^{\circ}$ of valgus, varus or retroversion and deemed to be poor if it was more than $10^{0}$ of the same. In cases with a stable fracture pattern full weight bearing walking was started immediately while it was delayed in unstable fracture types. Intravenous antibiotics were given for 3 days postoperatively and wound inspections were done on the $3^{\text {rd }}$ and $5^{\text {th }}$ postop day. Suture removal was done on the $12^{\text {th }}$ postop day. At discharge, all patients were advised to perform active mobilization of the hip, knee and ankle and to perform hip flexor and abductor strengthening exercises as taught and were asked to review at time periods of $1,3,6$ months and at yearly intervals thereafter. At follow up radiographs were taken and the fracture union was assessed periodically. Fracture union was defined to be nonvisualization of the fracture line on radiographs and absence of pain in the hip on weight bearing walking. Functional outcome evaluation was performed using Harris hip score and all scoring was done and documented in the case records. The data collected was analyzed using IBM SPSS Version 22.0. Armonk, NY: IBM Corp. Chi square test was used in the comparison of categorical variables. A $\mathrm{P}$ value of less than 0.05 was considered to be statistically significant. 
Case 1
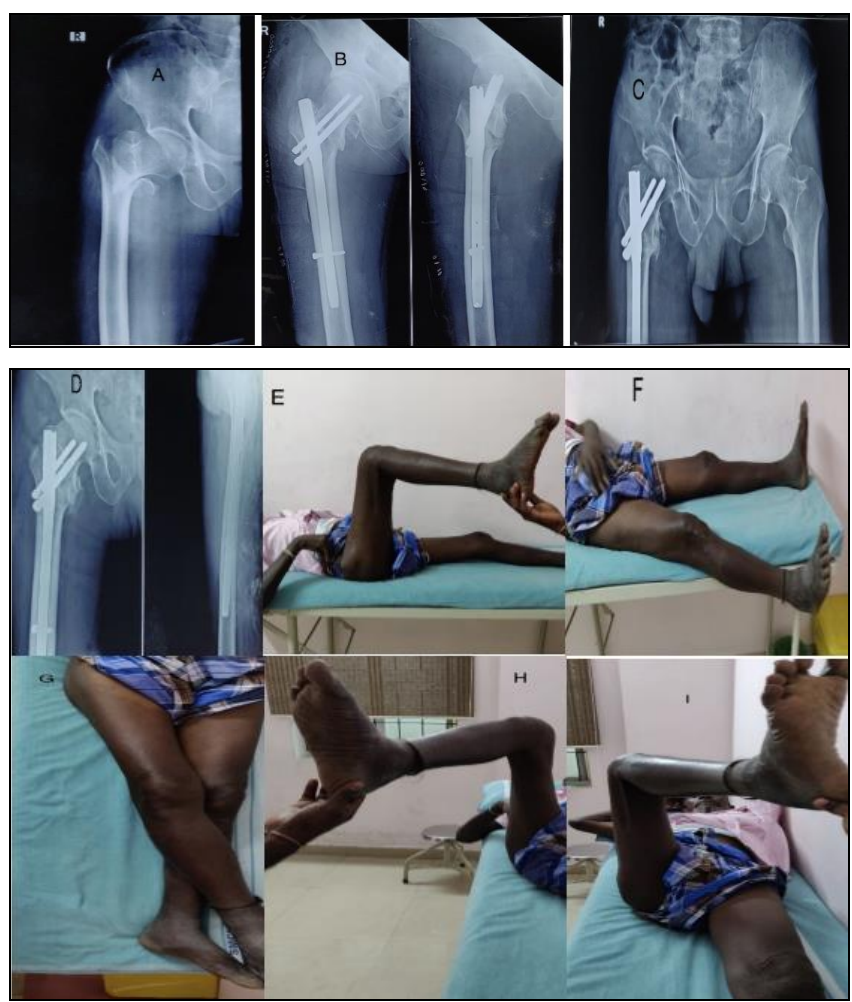

Fig 2: Illustrative cases

A. Preoperative $\mathrm{x}$ ray. B.1 month postop. C.3 months postop. D. X ray at 6 month follow up showing good union of the fracture. E. Good range of movements-Hip flexion.

F. Abduction. G. Adduction. H. Internal rotation. I. External rotation.

Case 2

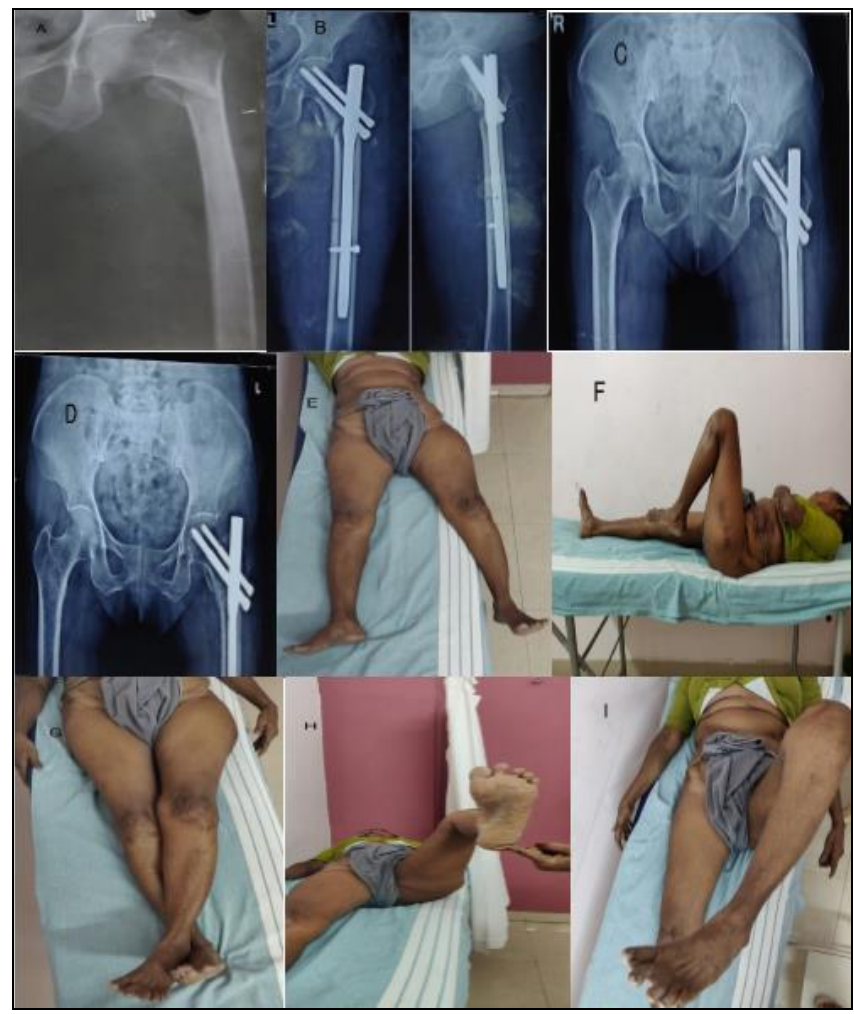

A. Preoperative $\mathrm{x}$ ray. B. Immediate post op x ray. C. Third month follow up.

D. X ray at one year showing good union of the fracture. E. Abduction. F. Flexion.

G. Adduction. H. Internal rotation. I. External rotation.

\section{Results}

The mean of the patients in our study was 62.1 years ranging from 48 to 85 years. There were 13 males and 17 females with the right hip being more commonly affected as seen in 17 of the patients.

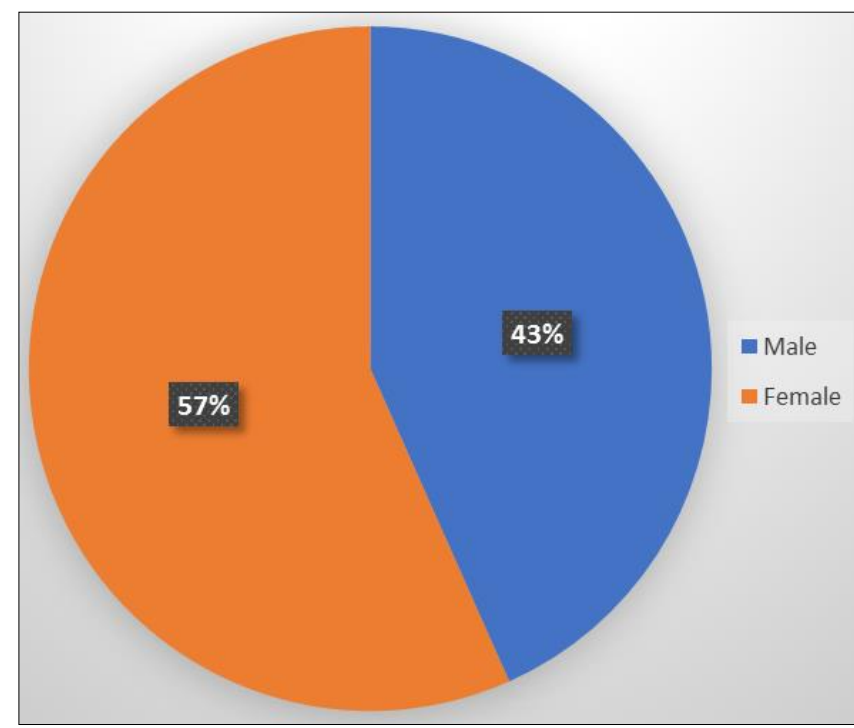

Fig 3: Gender distribution

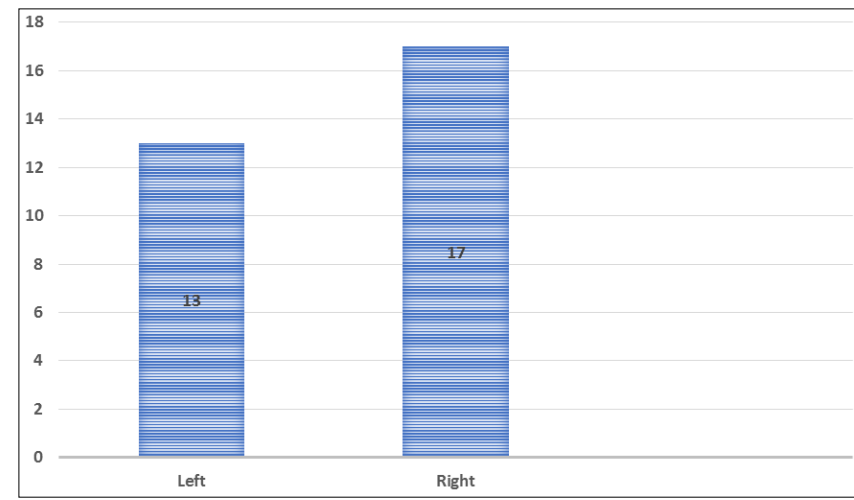

Fig 4: Side incidence

The most common mode of injury was slip and fall followed by road traffic accidents and fall from height. According to Kyles fracture classification, type 3 was the most common type followed by type 2 . The mean time from injury to presentation to the hospital was 7 days ranging from 2 to 15 days. The time from presentation to surgery was 3.6 days ranging from 2 to 7 days. The mean operative time was 59.03 minutes ranging from 47 to 74 minutes while the average blood loss was $49.9 \mathrm{ml}$ ranging from 35 to $62 \mathrm{ml}$. The mean time to fracture union was 12.4 weeks ranging from 10 to 15 weeks. The average time to weight bearing walking was 3.2 weeks ranging from 1 to 8 weeks. The mean Harris hip score was 83.3 ranging from 65 to 94 . The average range of movements achieved was Flexion- $105^{\circ}$, Abduction- $42^{0}$, Adduction- $25^{\circ}$, External rotation- $45^{\circ}$, and Internal rotation of $35^{\circ}$. According to Harris hip score we had excellent results in 5 patients, good in 12 while there were 3 patients with fair results and bad result in 1 patient. Complications such as superficial skin infection were seen in 2 patients which settled 
down well with a course of antibiotics while varus fixation was seen in 2 patients which was quite well tolerated by the patient. One of our patients had backout of both the neck screw and the hip pin which required a metal exit after one year after union of the fracture. There were no complications such as deep infection or nonunion encountered in our study. None of our patients were lost to follow up.

Table 1: Patient demographics and data

\begin{tabular}{|c|c|c|c|c|c|c|c|c|c|}
\hline $\begin{array}{l}\text { S. } \\
\text { No }\end{array}$ & Age & Sex & Side & \begin{tabular}{|c|}
$\begin{array}{c}\text { Mode } \\
\text { of } \\
\text { injury }\end{array}$ \\
\end{tabular} & $\begin{array}{l}\text { Classifi } \\
\text { cation }\end{array}$ & $\begin{array}{c}\text { Surgical } \\
\text { time } \\
\text { (minutes) }\end{array}$ & $\begin{array}{c}\text { Blood } \\
\text { loss } \\
(\mathrm{ml}) \\
\end{array}$ & $\begin{array}{c}\text { Time to } \\
\text { union } \\
\text { (weeks) }\end{array}$ & \begin{tabular}{|c|} 
Harris \\
hip \\
score
\end{tabular} \\
\hline 1 & 64 & $\mathrm{M}$ & $\mathrm{L}$ & SAF & Type 1 & 74 & 40 & 11 & 94 \\
\hline 2 & 58 & $M$ & $\mathrm{~L}$ & RTA & Type 3 & 56 & 45 & 13 & 80 \\
\hline 3 & 60 & $\mathrm{M}$ & $\mathrm{R}$ & SAF & Type 3 & 54 & 54 & 14 & 75 \\
\hline 4 & 74 & $\mathrm{~F}$ & $\mathrm{R}$ & SAF & Type 1 & 50 & 52 & 12 & 85 \\
\hline 5 & 71 & $\mathrm{~F}$ & $\mathrm{R}$ & SAF & Type 2 & 47 & 48 & 15 & 91 \\
\hline 6 & 60 & $\mathrm{M}$ & $\mathrm{R}$ & RTA & Type 2 & 54 & 41 & 13 & 80 \\
\hline 7 & 52 & $\mathrm{~F}$ & $\mathrm{R}$ & RTA & Type 2 & 50 & 54 & 12 & 85 \\
\hline 8 & 48 & $\mathrm{M}$ & $\mathrm{R}$ & RTA & Type 3 & 64 & 60 & 11 & 90 \\
\hline 9 & 54 & $M$ & $\mathrm{~L}$ & RTA & Type 1 & 72 & 62 & 10 & 85 \\
\hline 10 & 64 & $\mathrm{~F}$ & $\mathrm{~L}$ & SAF & Type 3 & 62 & 58 & 15 & 90 \\
\hline 11 & 60 & $\mathrm{~F}$ & $\mathrm{R}$ & SAF & Type 3 & 60 & 45 & 12 & 85 \\
\hline 12 & 54 & $\mathrm{~F}$ & $\mathrm{R}$ & RTA & Type 2 & 56 & 51 & 13 & 75 \\
\hline 13 & 58 & $\mathrm{M}$ & $\mathrm{L}$ & FFH & Type 2 & 54 & 54 & 15 & 80 \\
\hline 14 & 85 & $\mathrm{M}$ & $\mathrm{R}$ & SAF & Type 3 & 59 & 40 & 12 & 65 \\
\hline 15 & 56 & $\mathrm{~F}$ & $\mathrm{R}$ & RTA & Type 3 & 63 & 47 & 13 & 84 \\
\hline 16 & 64 & $F$ & $\mathrm{R}$ & RTA & Type 2 & 48 & 54 & 11 & 88 \\
\hline 17 & 58 & $\mathrm{~F}$ & $\mathrm{~L}$ & FFH & Type 2 & 53 & 35 & 10 & 84 \\
\hline 18 & 50 & $\mathrm{~F}$ & $\mathrm{~L}$ & RTA & \begin{tabular}{|l} 
Type 1 \\
\end{tabular} & 61 & 40 & 11 & 90 \\
\hline 19 & 56 & M & $\mathrm{R}$ & SAF & Type 3 & 70 & 45 & 13 & 88 \\
\hline 20 & 62 & $\mathrm{M}$ & $\mathrm{R}$ & RTA & Type 3 & 74 & 54 & 14 & 80 \\
\hline 21 & 58 & $\mathrm{~F}$ & $\mathrm{~L}$ & RTA & Type 2 & 58 & 50 & 12 & 82 \\
\hline 22 & 54 & $\mathrm{~F}$ & $\mathrm{~L}$ & FFH & Type 1 & 49 & 60 & 11 & 86 \\
\hline 23 & 62 & $F$ & $\mathrm{R}$ & SAF & Type 1 & 51 & 58 & 13 & 88 \\
\hline 24 & 74 & $\mathrm{M}$ & $\mathrm{L}$ & SAF & Type 1 & 62 & 62 & 14 & 85 \\
\hline 25 & 70 & $\mathrm{~F}$ & $\mathrm{~L}$ & SAF & Type 2 & 64 & 56 & 12 & 80 \\
\hline 26 & 68 & $\mathrm{~F}$ & $\mathrm{R}$ & FFH & Type 1 & 58 & 40 & 11 & 85 \\
\hline 27 & 65 & $\mathrm{M}$ & $\mathrm{R}$ & RTA & Type 3 & 56 & 45 & 10 & 92 \\
\hline 28 & 66 & $\mathrm{~F}$ & $\mathrm{~L}$ & FFH & Type 2 & 54 & 42 & 12 & 88 \\
\hline 29 & 73 & $\mathrm{~F}$ & $\mathrm{R}$ & SAF & Type 2 & 70 & 52 & 13 & 86 \\
\hline 30 & 68 & $\mathrm{M}$ & $\mathrm{L}$ & SAF & Type 1 & 68 & 54 & 14 & 85 \\
\hline
\end{tabular}

M-Male; F-Female; L-left; R-Right; RTA-Road traffic accidents, FFH-Fall from height; SAF-Slip and fall.

Table 2: Results according to Harris hip score

\begin{tabular}{|c|c|c|c|}
\hline S. No & Functional grading & No of patients & Percentage \\
\hline 1 & Excellent & 5 & 16.66 \\
\hline 2 & Good & 12 & 40 \\
\hline 3 & Fair & 2 & 6.66 \\
\hline 4 & Poor & 1 & 3.33 \\
\hline
\end{tabular}

\section{Discussion}

Intertrochanteric fractures of the femur are fairly common injuries and various modalities of treatment are available in the management of these fractures. They have a bimodal age distribution with fractures in the younger population occurring due to high energy trauma while fractures in the elderly age group occurring after trivial injuries due to poor bone stock. The aim of fracture management especially in the elder age group would be to stabilize the fracture surgically and to mobilize the patients as early as possible due to the fact that most of these patients would have associated comorbid conditions and early mobilization would prevent complications caused due to prolonged recumbency. Various implants are available for the fixation of these fractures and they have been evolving over the years $[9,10]$. The surface implants are the DHS and PFLP while the intramedullary ones are the gamma nail and the PFN ${ }^{[11,12]}$. The DHS had been the implant of choice for the fixation of intertrochanteric fractures over a period of years but they have been found to be suitable for more stable fracture patterns as compared to unstable types where the results have not been that great and is associated with complications such as uncontrolled collapse, lag screw migration leading to varus collapse at the fracture site and cut out of the screw due to failure to slide ${ }^{[13,}$ 14]. The gamma nail was in common use in earlier times but advances in nail patterns over time has reduced its usage due to the fact that it does not provide good rotational stability. The PFLP is a good option in unstable fractures but is associated with a wide skin incision, extensive soft tissue dissection with increased blood loss and a longer surgical time and the need to put the patient on non-weight bearing till the fracture has united completely. In this scenario, the PFN has many advantages over the other implants in factors such as less soft tissue dissection, shorter operating times, less blood loss, reduced incidence of infection and wound complications. It's a load sharing device so that early weight bearing walking can be started in stable fracture patterns and in cases of unstable fractures still earlier than with the use of a plate. The PFN provides stability by providing controlled fracture impaction. It has a shorter lever arm and there are less chances of mechanical failure due to decreased bending movement and also provides a buttress effect to prevent medialization of the shaft ${ }^{[15,16]}$. It does have its complications such as screw cut out, varus collapse, increased prominence of the nail causing a trochanteric bursitis, abductor compromise especially in younger patients. There are 2 phenomena associated known as the $\mathrm{Z}$ and reverse $\mathrm{Z}$ effect. A $Z$ effect happens when the antirotation screw is longer than the neck screw leading to increase vertical forces which promotes cut out with the antirotation pin migrating medially and the neck screw moving laterally while the opposite happens in reverse $\mathrm{Z}$ effect. We generally paid attention to a good anatomic reduction of the fracture with proper placement of the neck and antirotation screw and we did not encounter these complications. Regarding the entry point we would advise taking a more medial entry in the piriformis fossa in cases where the entry point lies directly at the fracture site. The results in our study were evaluated by the Harris hip score and we were able to achieve excellent results in 5 patients and good results in 12 of then. The one poor results we had was an 85 year old female with severe osteoporosis who had backing out of the screws with a mild varus collapse. We had to perform an implant removal after union at the fracture site. There were minor complications such as superficial skin infections and mild varus fixation which were inconsequential. In Asad et al. study of 91 patients, the mean age was 47.66 years with fracture union occurring at a mean time of 13 weeks. They had excellent outcomes in $28.6 \%$ of cases with good outcome in $45 \%$ while it was poor in $9.9 \%$ of cases ${ }^{[17]}$. Korhan et al. studied 24 patients with intertrochanteric fractures and reported a fracture union time of 14 weeks with excellent results in 14 cases and poor result in 1 case while 9 had fair results ${ }^{[18]}$. In Preteesh at all study of 50 patients the reported union time was 12 weeks with excellent results in $64 \%$ of cases, good in $24 \%$, fair in $8 \%$ and poor in $4 \%$ of cases ${ }^{[19]}$. The results of our study were fairly comparable to the studies of these authors as well as that of others as available in literature. We hereby conclude by stating that PFN is an effective treatment option in the management of intertrochanteric fractures of the femur and provides a good biomechanically stable construct with less surgical time and exposure, minimal blood loss, lesser chances of infection and wound complications and also 
facilitates early mobilization and weight bearing.

\section{Conclusion}

PFN in the management of intertrochanteric fractures of the femur provides a biomechanically stable construct and facilitates early mobilization and weight bearing to the patients in order to prevent complications due to prolonged recumbency, especially in the elderly age group. Proper anatomic reduction of the fracture is to be aimed for in order to prevent varus collapse at the fracture site and to prevent screw cutout. Proper placement of the neck screw and the hip pin to prevent a $Z$ and reverse $Z$ effect is desirable. In cases where the fracture lies at the entry point, a more medial entry at the piriformis fossa would be recommended.

\section{Declaration}

Funding: None

Conflict of interest: None declared

Ethical approval: Approval taken from the ethical committee.

\section{References}

1. Dimon JH, Hughston JC. Unstable intertrochanteric fractures of the hip. J Bone Joint Surg Am. 1967; 49(3):440-50.

2. Melton LJ 3rd, Kearns AE, Atkinson EJ, Bolander ME, Achenbach SJ, Huddleston JM. et al. Secular trends in hip fracture incidence and recurrence. Osteoporos Int. 2009; 20(5):687-94.

3. Hardy DC, Drossos K. Slotted intramedullary hip screw nails reduce proximal mechanical unloading. Clin Orthop Relat Res. 2003; 406:176-184.

4. Ho M, Garau G, Walley G, Oliva F, Panni AS, Longo UG, Maffulli N. Minimally invasive dynamic hip screw for fixation of hip fractures. Int Orthop, 2008. doi:10.1007/s00264-008-0565-4

5. Kyle RF, Wright TM, Burstein AH. Biomechanical analysis of the sliding characteristics of compression hip screws. J Bone Joint Surg Am. 1980; 62(8):1308-14.

6. Saudan M, Lübbeke A, Sadowski C, Riand N, Stern R, Hoffmeyer P. et al. Pertrochanteric fractures: is there an advantage to an intramedullary nail? A randomized, prospective studyof 206 patients comparing the dynamic hip screw andproximal femoral nail. J Orthop Trauma. 2002; 16(6):386-93.

7. Pajarinen J, Lindahl J, Michelsson O, Savolainen V, Hirvensalo E: Pertrochanteric femoral fractures treated with a dynamic hip screw or a proximal femoral nail. A randomised study comparing post-operative rehabilitation. J Bone Joint Surg Br. 2005, 87:76-81. 10.1302/0301-620X.87B1.15249.

8. Parker MJ, Bowers TR, Pryor GA. Sliding hip screw versus the Targon PF nail in the treatmentof trochanteric fractures of the hip: a randomised trial of 600 fractures. J Bone Joint Surg Br. 2012; 94:391-397. 10.1302/0301620X.94B3.28406.

9. Zhao C, Liu DY, Guo JJ, Li LP, Zheng YF, Yang HB. et al. Comparison of proximal femoral nail and dynamic hip screw for treating intertrochanteric fractures. Zhongguo Gu Shang. 2009; 22(7):535-7.

10. Pajarinen J, Lindahl J, Michelsson O, Savolainen V, Hirvensalo E. Pertrochanteric femoral fractures treated with dynamic hip screws or a proximal femoral nail: A randomized study comparing post-operative rehabilitation. J Bone Joint Surg Br. 2005; 87(1):76-81.
11. Takigami I, Matsuoto k, Ohara A, Yamanaka K, Naganawa T, Ohashi M. et al. Treatment of trochanteric fractures with PFNA nails system- report of early results. Bull NYU Hosp Jt Dis. 2008; 66(40):276-79.

12. Yaozeng X, Dechun G, Huilin Y, Guangming Z, Xianbin W. Comparative study of trochanteric fracture treated with proximal femoral nail antirotation and third generation of gamma nail. Injury. 2010; 41(7):986-90.

13. ET Su, DeWal H, Sanders R, Kummer FJ, Mu-jtaba M, Koval KJ. et al. Effect of Piriformis versus Tro-chanteric Starting Point on Fixation Stability of Short Intramedullary Reconstruction Nails. Bulletin Hospital for Joint Diseases. 2001; 60(2):67-71.

14. Hak DJ, Bilat C. Avoiding varus Malreduction during Cephalomedullary Nailing of Intertrochanteric Hip Fractures. Archives of Orthopaedic and Trauma Surgery. 2011; 131(5):709-710.

15. Anglen JU, Weinstein JN. Nail or plate fixation of intertrochanteric fractures: changing pattern of practice. A review of the American Board of Orthopaedic Surgery database. J Bone Joint Surg Am. 2008; 90(4):700-717.

16. Al-Yassari G, Langstaff RJ, Jones JWM, Al-Lami M. The AO/ASIF proximal femoral nail (PFN) for the treatment of unstable femoral fracture. Injury. 2002; 33:395-399.

17. Asad KG, Syed KAS, Muhammad AK, Muhammad AG, Muhammad KRN. Role of Proximal Femoral Nail in the Treatment of Unstable Intertrochanteric Fractures. Biomed J Sci \& Tech Res, 2018; 2(1). BJSTR. MS.ID.000645. DOI: 10.26717/BJSTR.2018.02.000645

18. Korhan O, Koray U, Can D, Mustafa C, Engin E. Distal unlocked proximal femoral intramedullary nailing for intertrochanteric femur fractures. International Orthopaedics (SICOT). 2009; 33:1397-1400. DOI 10.1007/s00264-008-0673-1.

19. Endigeri P, Pattanashetty OB, Banapatti DB, Pillai A, Ullas T. Outcome of intertrochanteric fractures treated with proximal femoral nail: A prospective study. J Orthop Traumatol Rehabil. 2015; 8:25-9. 